\title{
Surface and Volumetric Phenomena on Polyaniline
}

\section{Supported Electrocatalysts}

\author{
Graziela C. A. Ferreira, ${ }^{1}$ Mohmmad Khalid, ${ }^{1}$ Teko W. Napporn, ${ }^{2}$ Roberto M. Torresi, ${ }^{3}$ \\ Hamilton Varela, ${ }^{1, *}$ \\ ${ }^{1}$ São Carlos Institute of Chemistry, University of São Paulo, PO Box 780, 13560-970, São \\ Carlos, SP, Brazil \\ ${ }^{2}$ Université de Poitiers, IC2MP UMR 7285 CNRS, 86073 Poitiers Cedex 09, France \\ ${ }^{3}$ Departamento de Química Fundamental, Instituto de Química, Universidade de São Paulo, \\ Av. Prof. Lineu Prestes 748, 05508-000 São Paulo, Brazil
}

\begin{abstract}
Conducting polymers have been used as support for catalysts towards distinct electrocatalytic reactions. The overall activity of the modified interfaces critically depends on both the processes on the catalyst surface and of the charge compensation within the polymer matrix. Therefore, understand the coupling between surface and volumetric processes in such systems is of utmost importance. In this contribution we report on the experimental investigation of the interplay between surface and volumetric processes during the electrooxidation of formic acid (and also formaldehyde) on platinum modified polyaniline electrodes. The study was performed through in situ nanogravimetry, with the Electrochemical Quartz Crystal Nanobalance (EQCN). We have explored the dynamics of charge and mass changes along several experimental conditions, including the self-organized potential oscillations. The systematic study included the analysis of several configurations: gold electrodes covered with a PANI film and dispersed platinum (Au/PANI/Pt); platinum electrodes covered with PANI (Pt/PANI); and bare platinum electrodes. The methodology introduced includes the detailed analysis of the charge compensation process and of the time-derivative of the mass variations. Typical results for the electro-oxidation of formic acid on PANI supported platinum indicate that the electrocatalysis itself is reflected in the current profile, whereas the charge compensation rules the gravimetric response. This general observation also holds for the oscillatory electro-oxidation of formic acid. The physicochemical description of the support/catalyst systems described here opens interesting perspectives for the investigation of parent systems.
\end{abstract}

Keywords: electrocatalysis, formic acid, platinum, polyaniline, potential oscillations, EQCN.

* Corresponding author: hamiltonvarela@usp.br (HV) 


\section{INTRODUCTION}

Organic conducting polymers (e.g. polyaniline, polypyrrole, polythiophene, poly $(3,4-$ ethylenedioxythiophene) have been successfully employed in a wide range of applications, including functional electrochemical interfaces. ${ }^{1-4}$ Their use as matrices for immobilization of dispersed catalysts was initially motivated by their high conductivity in acidic media, high surface area and porous structure. ${ }^{5-7}$ Among them polyaniline (PANI) ${ }^{3}$ has particularly attracted much attention as catalyst support for low temperature fuel cells applications, ${ }^{1}$ because of its easy processability, high surface area, tunable electrical conductivity, flexibility, environmental stability and low cost. In fact, the electrocatalytic activity of interfaces consisting of PANI and platinum $(\mathrm{Pt})$ has been considered in the electro-oxidation of several small organic molecules. ${ }^{8-}$ 17

The high electrocatalytic activity of PANI/Pt modified electrodes towards the electrooxidation of small organic molecules has been found to be more promising, mainly because of the suppression of the adsorption of carbon monoxide (CO), which is known to be a poisonous species for the active sites of catalyst. Planes et al. ${ }^{18}$ investigated the electro-oxidation of methanol and $\mathrm{CO}$ on platinum electrodes covered with PANI and did not observe the characteristic infra-red (IR) signature of the adsorbed $\mathrm{CO}\left(\mathrm{CO}_{\mathrm{ad}}\right)$. Those IR bands were observed only when $\mathrm{CO}$ was bubbled in the electrolyte solution and oxidized, indicating that $\mathrm{CO}$ adsorption was not inhibited by the polymer layer. But the formation of $\mathrm{CO}_{\text {ad }}$ during the electro-oxidation of methanol was found to be suppressed. These results were extended to $\mathrm{Pt}$ nanoparticles deposited in the polymer film and the consistence of the results led the authors to suggest an alternative, non- $\mathrm{CO}_{\text {ad }}$ pathway in the oxidation mechanism of methanol on PANI modified electrodes. ${ }^{18}$ However, in spite of the interesting report on non-COad pathway of methanol electro-oxidation, the interaction between volumetric (charge compensation within the polymeric matrix) and surface (the electrocatalysis itself) phenomena that takes place in electrocatalysts dispersed in electronically conducting polymers, remains apparently unaddressed. This is the main contribution of the present report.

The Electrochemical Quartz Crystal Nanobalance (EQCN) is the technique-of-choice for the study of small mass variations at the electrode surfaces due to processes such as adsorption/desorption, electrocatalysis, corrosion, volumetric changes in polymer matrices, etc. ${ }^{19-24}$ This technique is based on the piezoelectric effect, property of certain materials to generate an electrical field when submitted to deformations or external pressure. In particular, 
the EQCN uses the inverse piezoelectric effect, where an electrical field is applied through the quartz crystal by two metallic films at both sides of the crystal, ${ }^{19,25}$ see below. Frequency changes can be related with mass variations on electrode surface by means of the Sauerbrey equation. ${ }^{19,26}$ Charge compensation process that follow the oxidation/reduction within the polymer matrix has been successfully discussed with the EQCN. ${ }^{21,27}$ In this process, there is an insertion/expulsion of ionic species (and also solvent molecules) within the polymeric matrix coupled to the electric current that flows through the metal/polymer interface, in order to maintain the electroneutrality. Importantly, this process is intrinsically coupled to electrocatalytic reactions in modified electrodes.

Conducting polymers are key materials for applications in actuators, transducers, and artificial muscles, ${ }^{28-30}$ and the coupling with self-organized current/potential oscillations that occur along the electro-oxidation of small organic molecules is very attractive. ${ }^{31-34}$ Inzelt and Kertész, ${ }^{12}$ studied the potential oscillations and the corresponding frequency changes with an EQCM (Electrochemical Quartz Crystal Microbalance) in the course of galvanostatic oxidation of formic acid on a platinized platinum electrode bare and covered with PANI films. The authors analyzed the effect of the pseudocapacitance of the PANI film on the increase of the oscillation period, and observed that the periodical mass changes along the oscillations increase during insertion/expulsion of counterions within the film.

In this paper, we investigate the interplay between surface and volumetric processes during the electro-oxidation of formic acid (and also formaldehyde) on platinum modified polyaniline electrodes. In particular, we explore the dynamics of charge and mass changes along several experimental conditions, including the self-organized potential oscillations observed under galvanostatic regime. To reach this goal, the systematic study comprises the investigation of several configurations: (a) gold electrodes covered with a PANI film and dispersed platinum (Au/PANI/Pt); (b) platinum electrodes covered with PANI (Pt/PANI); and (c) bare platinum electrodes, for comparison.

\section{EXPERIMENTAL}

General. All electrochemical experiments were conducted in a 3-electrode cell developed in our Group and it is coupled to the conventional EQCN cell provided by Metrohm, see Figure S1 in Supporting Information file for details. Electrochemical and nanogravimetric experiments were carried out with commercial working electrodes, provided by Metrohm Autolab. They 
consisted of quartz crystal (AT-cut with $6 \mathrm{MHz}$ ) covered with a thin layer of gold or platinum, of geometric area $0.36 \mathrm{~cm}^{2}$. In the case of the platinum film, the electrode roughness was estimated by the charge of hydrogen adsorption and amounts to about 1.5 . The counter electrode (gold or platinum plate, according to the working electrode used) with geometric area of 1.6 $\mathrm{cm}^{2}$ was used and Reversible hydrogen electrode (RHE) was employed as a reference electrode. All experimental data were acquired with Autolab PGSTAT320N potenciostat/galvanostat, and EQCN modulus with resolution of $0.07 \mathrm{~Hz}$.

Modified electrodes. The procedure to deposit polyaniline on gold and platinum-covered quartz crystals was identical in both cases. The electrochemical polymerization was performed by sequence of several voltammetric cycles at $50 \mathrm{mV} \mathrm{s}^{-1}$ : the first cycle was between 0.05 and $1.10 \mathrm{~V}$ to allow the first aniline molecules to deposit on the surface and promote the polymerization; and the forward cycles was stetted between 0.05 and $1.00 \mathrm{~V}$ to avoid the higher oxidation of PANI film. ${ }^{8,35,36}$ An aqueous solution with $0.10 \mathrm{~mol} \mathrm{~L}^{-1}$ of aniline monomers and $0.5 \mathrm{~mol} \mathrm{~L}^{-1}$ of $\mathrm{H}_{2} \mathrm{SO}_{4}$ was used. The polymerization procedure was interrupted when the peak current density in the voltammogram reached to a certain value, which could be related to the desired thickness of $125 \mathrm{~nm}$ approximately, roughly estimated by the methodology employed by Stilwell and Park. ${ }^{36}$ Gold and platinum electrodes electrodeposited of polyaniline films were designed as Au/PANI and Pt/PANI, respectively. After polymerization, in order to remove traces of aniline and oligomers, the working electrode was gently rinsed with ultrapure water, placed in a clean electrochemical cell, and several voltammetric cycles were performed between $0.05 \mathrm{~V}$ and $0.90 \mathrm{~V}$ in aqueous $0.5 \mathrm{~mol} \mathrm{~L}^{-1} \mathrm{H}_{2} \mathrm{SO}_{4}$ solution (as a base electrolyte used in our experiments), until a time-invariant electrochemical response is observed.

Platinum nanoparticles were deposited on Au/PANI electrodes from a solution of 0.2 mmol L-1 hexachloroplatinic acid hexahydrate prepared in aqueous $0.5 \mathrm{~mol} \mathrm{~L}^{-1} \mathrm{H}_{2} \mathrm{SO}_{4}$ solution. The deposition was carried out by applying $0.50 \mathrm{~V}$ for 90 seconds. After that, the working electrode was rinsed with ultrapure water, the electrochemical cell was replaced with a clean one, and several voltammetric cycles were performed between $0.05 \mathrm{~V}$ and $0.90 \mathrm{~V}$ in electrolytic solution. The deposited platinum load was about $250 \mathrm{ng} \mathrm{cm}^{-2}$; and the platinum domains dispersed on PANI film were about $100-200 \mathrm{~nm}$ in diameter. Those modified electrodes are denoted as Au/PANI/Pt. The spongy-like structure of PANI allows a homogeneously deposition of platinum nanoparticles. The results indicate a good dispersion of Pt nanoparticles and absence of Pt clusters with significant size which can lead to the appearance of characteristics of the bulk metal in the voltammograms. 
All results obtained with PANI electrodes had current values normalized by the geometric area. Some $\Delta m$ data were averaged with the Origin program in order to reduce the noise when low mass variations are involved.

Solutions. The following chemicals were used in our experiments: sulfuric acid $\left(\mathrm{H}_{2} \mathrm{SO}_{4}\right)(95-$ $97 \%$, Merck), aniline (99,5\%, Sigma-Aldrich) (distilled twice before use), hexachloroplatinic acid hexahydrate $\left(\mathrm{H}_{2} \mathrm{PtCl}_{6} 6 \mathrm{H}_{2} \mathrm{O}\right)(99,9 \%$, Alfa Aesar), formic acid (HCOOH) $(98 \%$, SigmaAldrich), formaldehyde (HCHO) (37 \%, Sigma-Aldrich) and argon gas (99,996 \%, White Martins). All solutions were prepared in ultrapure water (Millipore Milli-Q 18.2 M $\Omega \mathrm{cm}$ at 20 ${ }^{\circ} \mathrm{C}$ ) and deaerated with argon gas for 15 minutes before each experiment. During the experiment, the gas flux was interrupted to avoid interferences in frequency of EQCN measurements. Formaldehyde was heated in a water bath at $60{ }^{\circ} \mathrm{C}$ for 10 minutes before the experiments to evaporate methanol in solution.

\section{RESULTS AND DISCUSSION}

Initial characterization. Stationary voltammetric responses of the platinum and gold films are given in Figure S2 in the Supporting Information. The current and mass profiles along the electro-polymerization of the aniline monomers at the metallic film on the quartz is given in Figure S3 in the Supporting Information file. Figure 1 shows the time-invariant voltammetric $j / E$ and $\Delta m / E$ profiles of the (a) PANI coated gold (Au/PANI) and (b) after immobilization of the platinum nanoparticles (Au/PANI/Pt). In addition, the $d(\Delta m) / d t v s$. E profile for the mass variation curve given in (b) is also presented in plate (c). For both modified electrodes, the cyclic voltammogram shows a couple of redox peaks at $0.42 / 0.30 \mathrm{~V}$, in the forward/backward sweep related to the conversion of leucoemeraldine into emeraldine, and vice versa. In the present study, all experiments were carried out in the potential range between $0.05 \mathrm{~V}$ and 0.90 $\mathrm{V}$ to prevent the overoxidation and degradation of the polymer, and it also guarantee the presence of emeraldine state, the most conductive form of PANI. Details of the oxidation states of PANI are given in Figure S4 in the Supporting Information. ${ }^{37-39}$ 


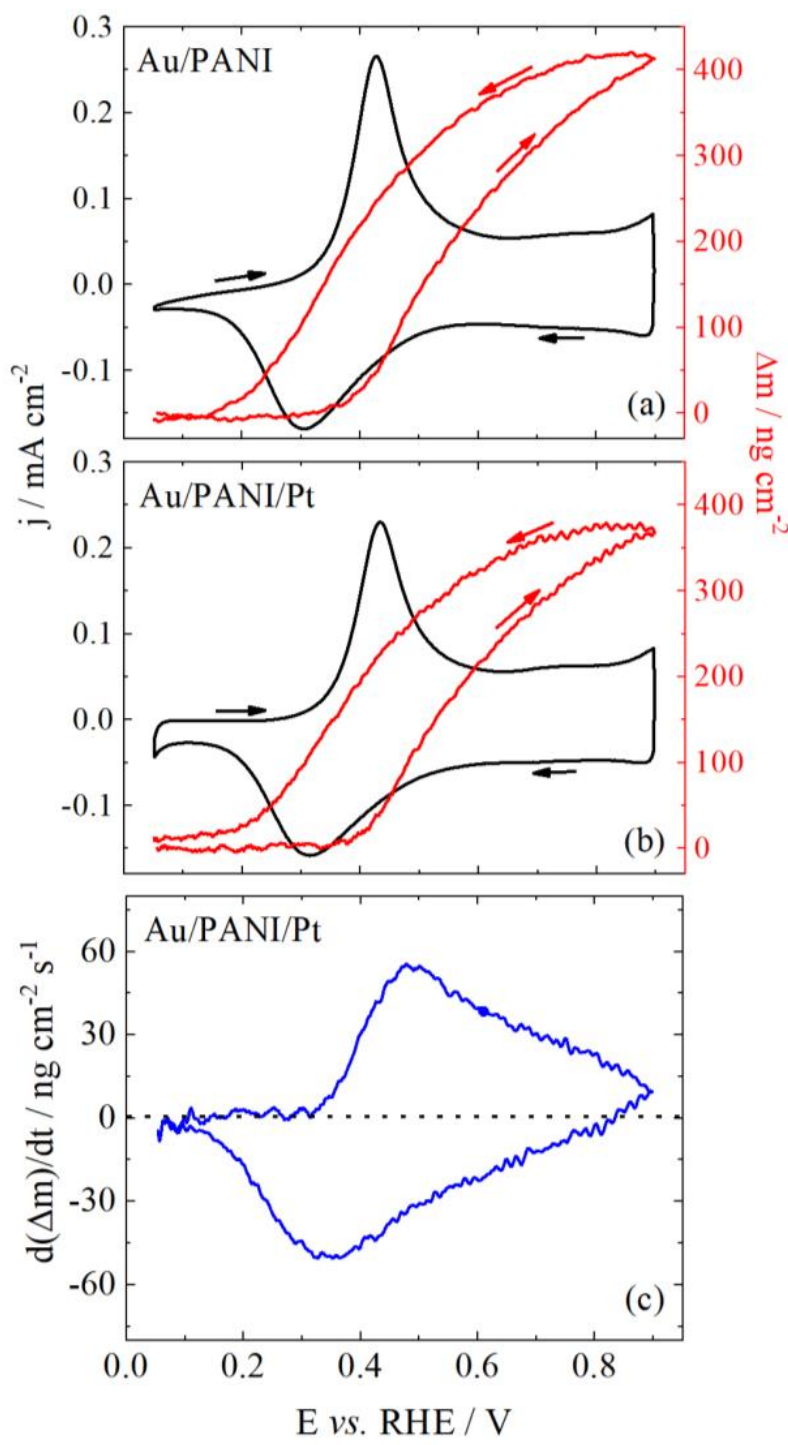

Figure 1: Voltammetric $j / E$ and $\Delta m / E$ profiles (recorded at $50 \mathrm{mV} \mathrm{s}^{-1}$ ) for (a) $\mathrm{Au} / \mathrm{PANI}$ and (b) Au/PANI/Pt modified electrodes. (c) $d(\Delta m) / d t v s$. $E$ for the mass variation profile given in (b). Electrolyte: aqueous solution containing $0.5 \mathrm{~mol} \mathrm{~L}^{-1}$ $\mathrm{H}_{2} \mathrm{SO}_{4}$. Current and mass were normalized by the geometric area of the electrode.

The $\Delta m / E$ profiles reflect the counter ion + water insertion and expulsion that follow the redox changes within the film, see below. Both profiles given in Figure 1 shows a continuous increase/decrease along the oxidation/reduction and a slightly higher mass is reached in the $\mathrm{Au} / \mathrm{PANI}$ electrode, which is due to the slightly large charge propagation in the voltammetric curve of Au/PANI. The similarity of the current and mass changes profiles in Figures 1(a) and (b) suggests that the low amount of platinum is immobilized in the Au/PANI/Pt modified electrode. The presence of platinum deposit can be inferred by the slight increase in the current density at low potentials due to the hydrogen interaction with platinum, and the slightly smaller 
redox charge in Figure 1(b)..$^{40}$ In any case, the small thickness of the film deposited on the quartz assured that it behaves rigidly, so that the eventual viscoelastic problems are likely to be neglected and the Sauerbrey equation holds. ${ }^{19}$ See Supporting Information for details.

Therefore, the mass variations presented in Figure 1 are dominated by the redox processes within the polymer film in both Au/PANI and Au/PANI/Pt modified electrodes. If the overall mass that flow through the composite (polymer/metal)/electrolyte interface to compensate the electron exchange at the metal/composite were to be exclusively due to, say, anions, the time-derivative of the mass variation would mirror the current profile, see Supporting Information for the correspondence between mass changes and charge and thus between $d(\Delta m) / d t$ and current $(d q / d t)$. The same would be true for the $-d(\Delta m) / d t$ and current curves if the mass would be dominated by cations. Figure 1(c) depicts the $d(\Delta m) / d t v s$. E curve for the $\Delta m$ profile for the Au/PANI/Pt electrode in Figure 1(b). Despite of some resemblance with the current profile, the mismatch is very clear. In particular, the pair of oxidation/reduction current peaks at $\sim 0.42 / 0.30 \mathrm{~V}$ is shifted to about $0.49 / 0.35 \mathrm{~V}$ for the $d(\Delta m) / d t v s$. $E$ curve. This discrepancy does not reflect the existence of different processes, but rather the fact that the oxidation/reduction of PANI is counterbalanced by the insertion/expulsion of electrolyte anions, cations, and, presumably, solvent molecules. ${ }^{41,42}$ This process is referred to as charge compensation and it is analyzed in the following.

Charge compensation within PANI films. The charge and mass balances can be used to estimate the flux of ionic species and solvent molecules along the redox processes within the polymer matrix. In this context, we used the approach discussed by Torresi and collaborators, ${ }^{21,27}$ to describe this dynamics, and details are given in the Supporting Information file. Once there are three species to be considered, i.e., cations, anions, and solvent molecules, and only two quantities are determined in the experiments, namely mass and charge, results are expressed in terms of the amount of cation + solvent and anion + solvent that enter or leave the film. This not necessarily mean that solvent molecules enter/leave film solvating ionic species, actually, they are grouped to the ionic flux because of the mathematical impossibility of discriminating the individual contributions of these three species. Figure 2 shows the number of mols of cation + water and anion + water $\left(\right.$ in $\mathrm{nmol} / \mathrm{cm}^{2}$ ) as a function of the electrode potential for the responses illustrated in Figure 1. The base cyclic voltammograms depicted in Figure 1 are also given for reference. Negative values of $\xi$ are referred to the ejection and positive values to the incorporation of species within the film. 


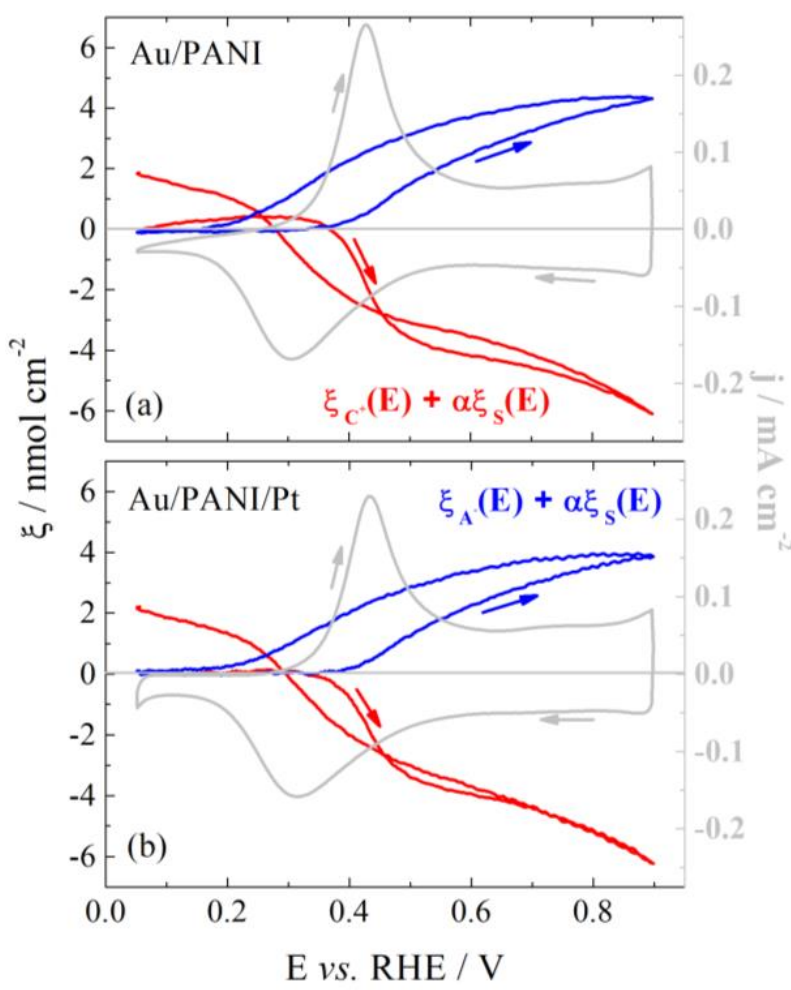

Figure 2: Estimated number of mols of cations + solvent and anions + solvent obtained from the data presented in Figure 1 for the (a) Au/PANI and (b) $\mathrm{Au} / \mathrm{PANI} / \mathrm{Pt}$ modified electrodes. See supporting Information for further details.

The increase of the electrode potential results in an increase in $\Delta m$, particularly around the current peak, as shown in Figure 1, and the charge compensation along this process is reached by both counter ion (and water) insertion and proton (and water) expulsion. During the negative-going sweep, the reverse occurs and the $\Delta m$ decrease reflects the insertion of protons + water and the expulsion of sulfate + water. These results are in full agreement with previously published data ${ }^{41,43}$ and attests that both anionic and cationic species take place in the charge compensation processes of PANI films. Importantly, as already anticipated by the $j / E$ and $\Delta m / E$ profiles given in Figure 1, the dynamics of charge compensation remains nearly unaffected by the presence of the platinum nanoparticles within the PANI film.

Electrocatalysis on PANI modified electrodes. Figure 3 shows the voltammetric $j / E$ and $\Delta m / E$ profiles of the electro-oxidation of formic acid ( $\mathrm{HCOOH}$ ) on (a) an EQCN electrode coated with a Pt film and on (b) Pt modified PANI electrode, Au/PANI/Pt. In the forward scan, on Pt electrode, as shown in Figure 3(a), there is a long range of potential characterized by very low reaction rates caused by the presence of adsorbed $\mathrm{CO}, \mathrm{CO}_{\mathrm{ad}}$, on $\mathrm{Pt}$, which severely poisons the surface of the catalyst. ${ }^{44}$ Besides some detectable current that flows at lower potentials, 
appreciable reaction rates are found above $0.90 \mathrm{~V}$ and starts decreasing again due to the oxidation of the platinum surface. Along this region, the $\Delta m$ shows a slow decrease and then a more abrupt one around the main oxidation wave in forward sweep. This behavior is in agreement with that obtained by Hachkar et $a l .{ }^{45}$ who have shown that the decrease in mass in this potential range is due to the presence of adsorbed $\mathrm{CO}$ species which promote the repulsion of water molecules. After that the surface oxidation results in a mass increased. In the backward sweep, the process is followed by a negative small $\Delta m$ variation due to $\mathrm{CO}$ adsorption until 0.90 $\mathrm{V}$. From this potential on, $\mathrm{CO}_{\mathrm{ad}}$ is oxidized and the mass decreases, releasing the free platinum sites for the oxidation of formic acid, which results in a current increase. This reaction generates a second oxidation peak followed by an abruptly decrease in mass response due to the reduction of the previously formed platinum oxide and the simultaneous oxidation of formic acid. Again, $\mathrm{CO}_{\mathrm{ad}}$ is formed and $\Delta m$ increases as the potential is decreased. 


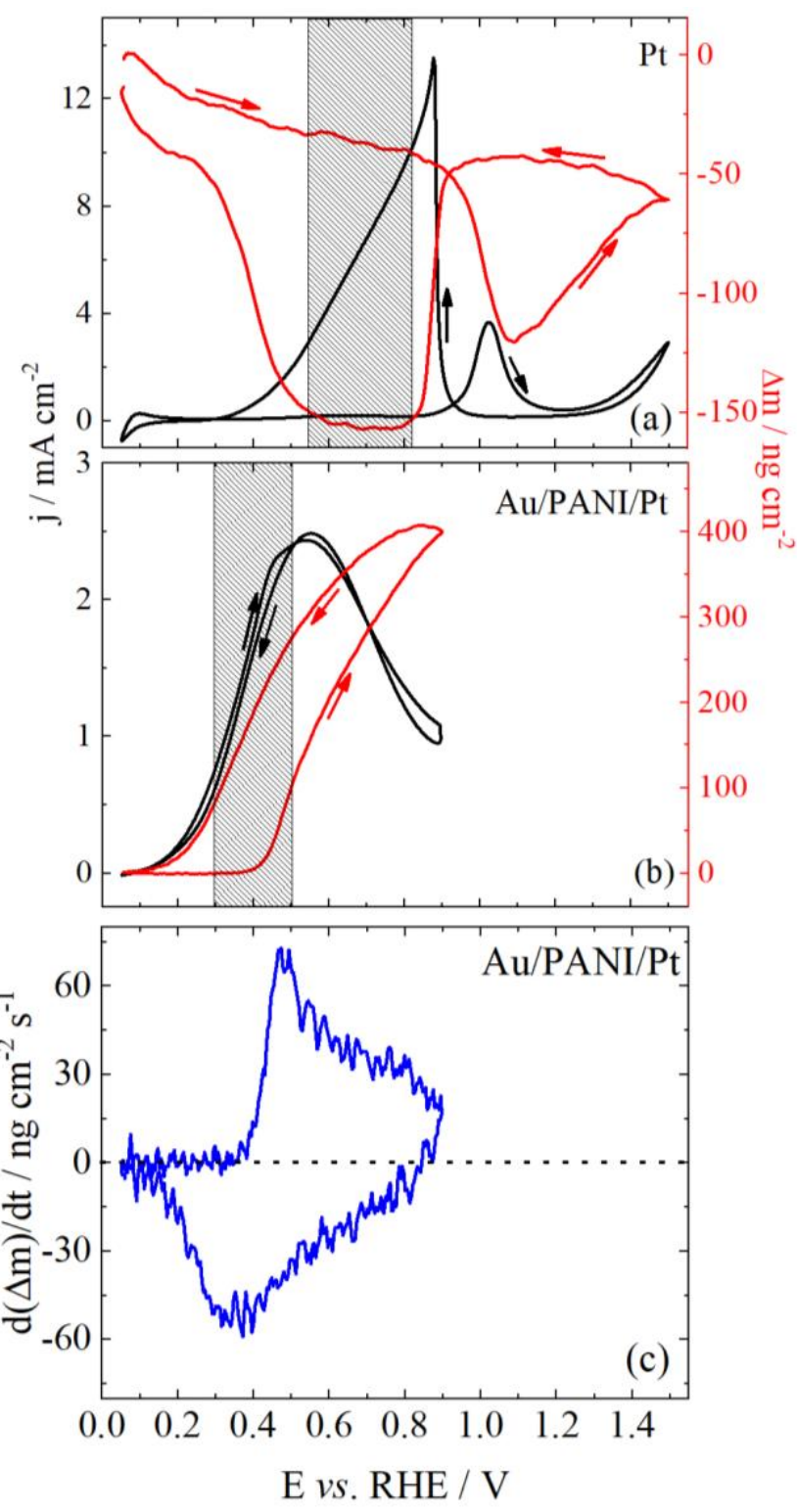

Figure 3: Voltammetric $j / E$ and $\Delta m / E$ profiles (recorded at $50 \mathrm{mV} \mathrm{s}^{-1}$ ) for (a) Pt and (b) Au/PANI/Pt electrodes. (c) $d(\Delta m) / d t v s$. $E$ for the mass variation profile given in (b). Electrolyte: aqueous solution containing $0.5 \mathrm{~mol} \mathrm{~L}^{-1} \mathrm{H}_{2} \mathrm{SO}_{4}$ and $1 \mathrm{~mol}$ $\mathrm{L}^{-1} \mathrm{HCOOH}$. The current and mass were normalized (a) by the electroactive area (Pt hydrogen area, see text for details), and (b) by the geometric area, as in Figure 1.

Figure 3(b) depicts the voltammetric $j / E$ and $\Delta m / E$ profiles of $\mathrm{Au} / \mathrm{PANI} / \mathrm{Pt}$ electrode for the electro-oxidation of $\mathrm{HCOOH}$. The electro-oxidation reaction starts at about $0.10 \mathrm{~V}$, and reaches currents about 10 times higher than before the addition of $\mathrm{HCOOH}$, as shown in Figure 1(b). Moreover, the ratio between the oxidation peaks in forward and backward scans, on $\mathrm{Au} / \mathrm{PANI} / \mathrm{Pt}$ electrode, is approximately 1 , whereas on bare $\mathrm{Pt}$ the ratio is 0.26 . The increase in peaks ratio indicates that $\mathrm{Au} / \mathrm{PANI} / \mathrm{Pt}$ catalyst is more tolerant against $\mathrm{CO}$ adsorption. In 
contrast, the $\Delta m / E$ profile remains rather unaffected by the presence of formic acid as clearly seen in Figures 1(b) and 3(b), indicating the prevalence of the volumetric effects due to the charge compensation processes within the film. As already discussed in Figure 1, the use of $d(\Delta m) / d t v s$. $E$ can be of help in this discussion. Results are given in Figure 3(c) for the $\mathrm{Au} / \mathrm{PANI} / \mathrm{Pt}$ system using the data presented in plate (b). As already anticipated by the $\Delta m v s$. $E$ curves, the similarity in the $d(\Delta m) / d t v s$. E profiles in the absence, Figure 1(c), and in the presence, Figure 3(c), of formic acid clearly confirm that predominance of the charge compensation process in the mass variations. In the light of the individual ionic (+solvent) contributions, it must be noted that the data presented in Figure 2(b) are given in nmol, and the mass of anion $\mathrm{HSO}_{4}{ }^{-}\left(97 \mathrm{~g} \mathrm{~mol}^{-1}\right)$ is considerably larger than that of protons, the cationic specie available. That is why the anion insertion/expulsion during the oxidation/reduction governs the $d(\Delta m) / d t$ curves.

Overall, it is clear from Figure 3 that the $d(\Delta m) / d t$ vs. $E$ profiles can emulate the voltammetric response of the volumetric processes, i. e. charge compensation, within the film, simultaneously to the conventional voltammetric response, in this case ruled by the surface electro-oxidation of formic acid on platinum dispersed in the polymeric matrix. We are not aware of similar analysis, and the resulting decoupling can be used to uncover the dynamics in several systems, including applications such as supported catalysts for energy conversion systems and actuators.

Oscillatory electro-oxidation of HCOOH on Pt and on Au/PANI/Pt electrodes. As in the case of many small organic molecules, the electro-oxidation of formic acid (and formaldehyde, see below) on platinum is known to undergo kinetic instabilities, such as potential and current oscillations, see ${ }^{34}$ and references therein. Potential oscillations have been particularly explored to improve the efficiency of low temperature fuel cells and electrolyzers. ${ }^{46-49}$ As already mentioned, exploring the self-organized current/potential oscillations in modified electrodes is important in several applications such as actuators, transducers, and artificial muscles, etc. In the following we discuss some aspects of the potential oscillations, recorded under galvanostatic regime, along the electro-oxidation of $\mathrm{HCOOH}$ on different electrode surfaces. Additional experiments with formaldehyde ( $\mathrm{HCHO})$ were also performed.

Figure 4 shows typical potential oscillations during the electro-oxidation of $\mathrm{HCOOH}$ on (a) Pt and on (b) Au/PANI/Pt electrodes. Potential oscillations on platinum electrode, Figure 4 (a), are faster $(3.3 \mathrm{~Hz})$, with amplitude of $200 \mathrm{mV}$, small mass variation per cycle (less than 6 $\left.\mathrm{ng} \mathrm{cm}^{-2}\right), E / t$ and $\Delta m / t$ evolutions are out-of-phase, i.e., $\Delta m$ decrease/increase when $E$ 
increase/decrease. On Au/PANI/Pt electrode potential oscillations, Figure 4(b), are much slower $(0.01 \mathrm{~Hz})$, with smaller amplitude (around $100 \mathrm{mV}$ ), larger mass variations (around 20 ng) and $E / t$ and $\Delta m / t$ evolutions are in-phase.

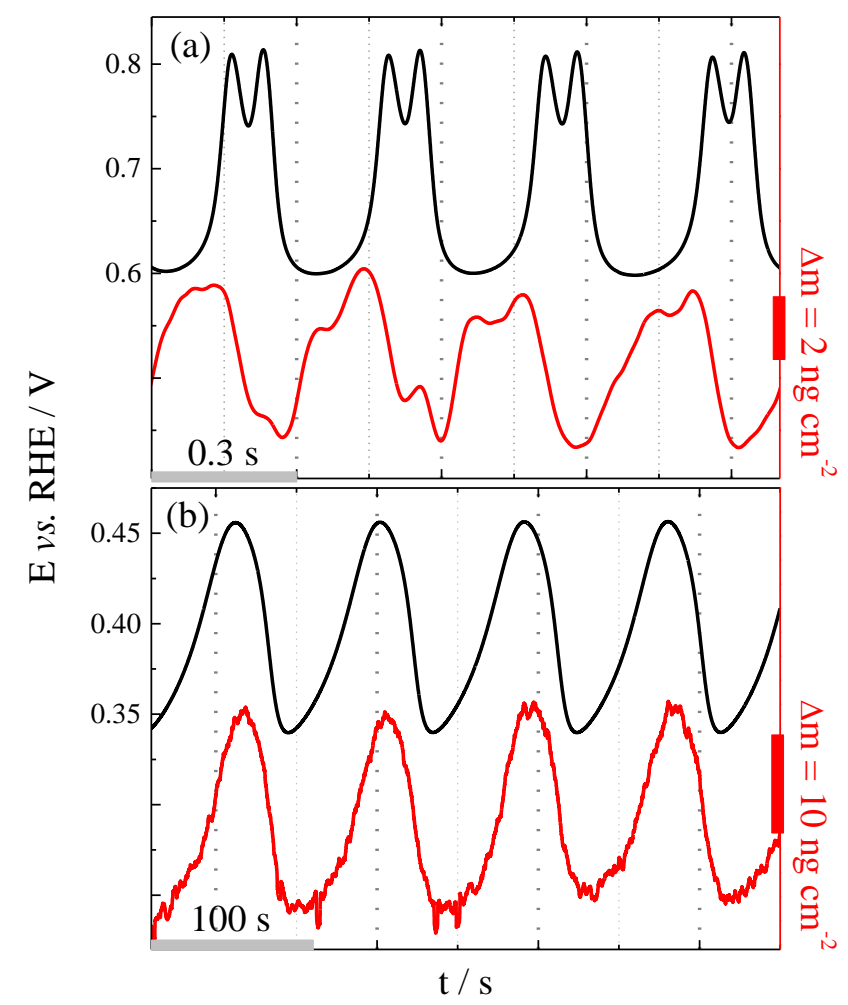

Figure 4: Potential oscillations along the electro-oxidation of $\mathrm{HCOOH}$ on (a) $\mathrm{Pt}$, at $1.29 \mathrm{~mA} \mathrm{~cm}$, and on (b) Au/PANI/Pt, at $0.28 \mathrm{~mA} \mathrm{~cm}^{-2}$. Electrolyte: aqueous solution containing $0.5 \mathrm{~mol} \mathrm{~L}^{-1} \mathrm{H}_{2} \mathrm{SO}_{4}$ and $1 \mathrm{~mol} \mathrm{~L}^{-1} \mathrm{HCOOH}$.

Potential windows where oscillations in Figure 4 are observed are given in the gray area in Figure 3 for both electrodes. Oscillations in the electrode potential in those systems typically occur prior to the main oxidation wave, as in the case found here on bare and on PANI-modified electrodes. Expectedly, the higher voltammetric activity, as shown in Figure 3(b), of the later is also evident in the smaller overpotentials found in the time-series in Figure 4(b). Noteworthy differences found in the time-series in Figure 4 are the mass variations and the oscillation frequency. On platinum electrode, the mass variations are exclusively due to the surface processes, such as (dissociative) adsorption, desorption, and oxidation and reduction of surface species, involving a few Pt monolayers at most. In contrast, on Au/PANI/Pt, the electrochemical activity strongly depends on the charge compensation already described. Indeed, the larger mass changes observed in the Au/PANI/Pt modified electrode is dominated by the volumetric process comprising the flux of ionic species and solvent molecules caused by the redox processes within 
the PANI film. In contrast to that found in during the cyclic voltammetry, c.f. Figure 1, in the case of the galvanostatic conditions as depicted in Figure 4(b), the oxidation/reduction of the PANI film are driven by the self-organized potential oscillations.

Given the relative similarities in the mechanism underlying the oscillatory electrooxidation of small organic molecules, ${ }^{34}$ we decided to carry out some experiments with formaldehyde $(\mathrm{HCHO})$ on bare platinum in order to compare with those with $\mathrm{HCOOH}$ given in Figure 4(a). The main idea here is to further investigate the phase between $E / t$ and $\Delta m / t$, and try to exclude any possible artifact that could be caused by the small variations in $\Delta m$ for the system $\mathrm{Pt}+\mathrm{HCOOH}$ presented in Figure 4(a). Time-series recorded during the galvanostatic electrooxidation of $\mathrm{HCHO}$ on platinum at two applied currents are shown in Figure 5. The higher potential amplitude typical for this system results in larger mass variations. As in the case of $\mathrm{HCOOH}$, oscillations in $E$ and $\Delta m$ are out-of-phase for both applied currents, corroborating thus the qualitative features discussed.

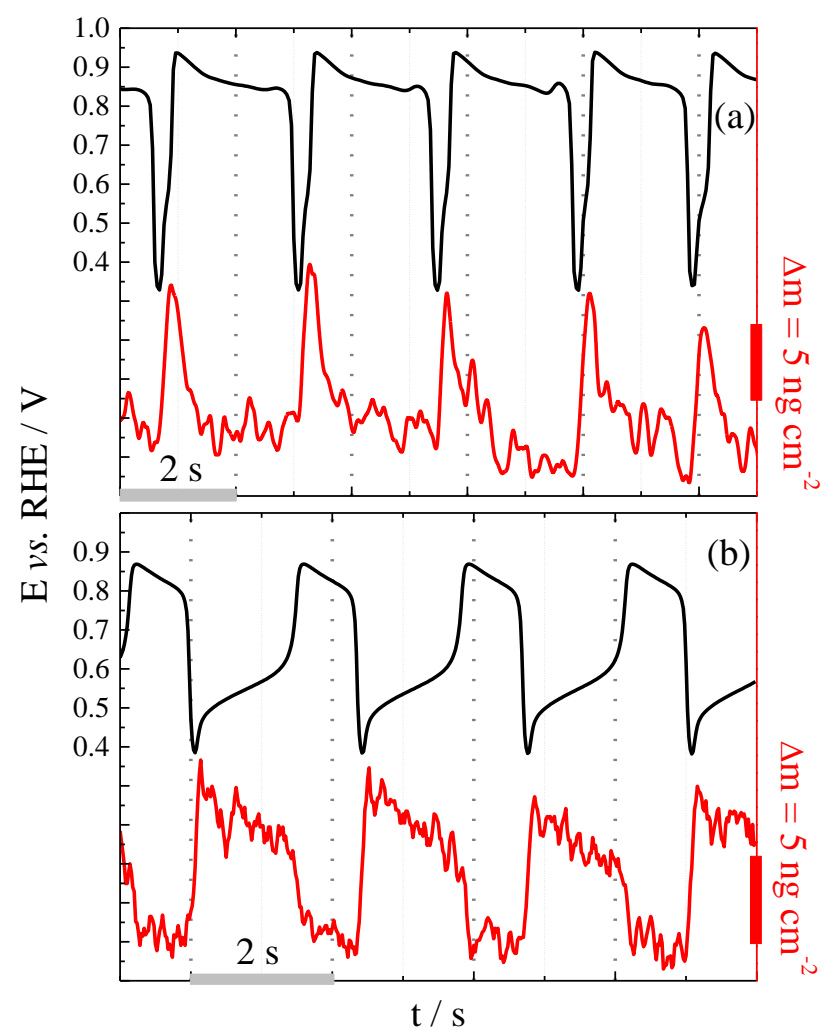

Figure 5: Potential oscillations along the electro-oxidation of $\mathrm{HCHO}$ on $\mathrm{Pt}$ at (a) 1.45 , and at (b) $0.4 \mathrm{~mA} \mathrm{~cm}^{-2}$. Electrolyte: aqueous solution containing $0.5 \mathrm{~mol} \mathrm{~L}^{-1}$ $\mathrm{H}_{2} \mathrm{SO}_{4}$ and $0.1 \mathrm{~mol} \mathrm{~L}^{-1} \mathrm{HCHO}$.

Features of the oscillations observed so far are compiled in Table 1. Results are given in terms of potential window visited during oscillations, amplitude of $E$ and $\Delta m$, oscillatory 
frequency and the relationship between $E / t$ and $\Delta m / t$; for the oscillatory electro-oxidation of $\mathrm{HCHO}$ and $\mathrm{HCOOH}$ on $\mathrm{Pt}$, and of $\mathrm{HCOOH}$ on $\mathrm{Au} / \mathrm{PANI} / \mathrm{Pt}$.

Table 1: Comparison between features of the potential oscillations obtained for different Pt electrodes during the electro-oxidation of $\mathrm{HCHO}$ and $\mathrm{HCOOH}$

\begin{tabular}{lccc} 
& $\mathrm{Pt}+\mathrm{HCHO}$ & $\mathrm{Pt}+\mathrm{HCOOH}$ & Au/PANI/Pt+HCOOH \\
potential window & $0.35-0.95 \mathrm{~V}$ & $0.60-0.80 \mathrm{~V}$ & $0.34-0.46 \mathrm{~V}$ \\
potential amplitude & $\sim 0.60 \mathrm{~V}$ & $\sim 0.20 \mathrm{~V}$ & $\sim 0.10 \mathrm{~V}$ \\
Am amplitude & $10 \mathrm{ng} \mathrm{cm}^{-2}$ & $6 \mathrm{ng} \mathrm{cm}^{-2}$ & $20 \mathrm{ng} \mathrm{cm}^{-2}$ \\
oscillatory frequency & $0.40-0.70 \mathrm{~Hz}$ & $3.30 \mathrm{~Hz}$ & $0.01 \mathrm{~Hz}$ \\
Elt and $\Delta$ m/t relationship & out-of-phase & out-of-phase & in-phase \\
\hline
\end{tabular}

Inzelt and coworkers ${ }^{23,50-52}$ studied the potential and mass variations in the oscillatory electro-oxidation of formic acid and 2-propanol on platinum. In both cases, the authors found that the $E / t$ and $\Delta m / t$ relationships are out-of-phase, as in the present case. They used rather rough Pt electrodes ( $f$ between 45 and 400), and otherwise comparable conditions than that adopted here. The same trend was also found by Tian and Conway, ${ }^{53}$ for the electro-oxidation of formic acid on platinum. However, the mass variations along the oscillations in this case is far less noisy. Overall, the agreement with those previously published suggests a universal trend in the $E / t$ and $\Delta m / t$ relationship for this type of system, where the dissociative adsorption of $\mathrm{CO}$ and its further oxidation are central to the emergence of oscillations. Inzelt and Kertész ${ }^{12}$ also studied the simultaneous potential and surface mass variations in the oscillatory electrooxidation of formic acid on bare and PANI-modified platinum electrodes. The study was carried out in aqueous solution containing $1 \mathrm{~mol} \mathrm{~L}^{-1} \mathrm{HClO}_{4}$ and $1 \mathrm{~mol} \mathrm{~L}^{-1} \mathrm{HCOOH}$. Results of mass variations on Pt seems rather noisy, as in our case, and not stationary. Nevertheless, the trends in the $E / t$ and $\Delta m / t$ relationships for Pt and PANI-modified Pt systems were identical to that found here, cf. Table 1. In the following we deepen the investigation of the contributions of surface and volumetric processes in PANI modified electrodes.

Surface and volumetric processes. Figure 6 shows the voltammetric, charge and mass variation profiles for the $\mathrm{Au} / \mathrm{PANI}$ electrode in presence of $\mathrm{HCOOH}$. In addition, the charge and mass variations recorded in the absence of $\mathrm{HCOOH}$, already presented in Figure 1(a), are also given for comparison. 


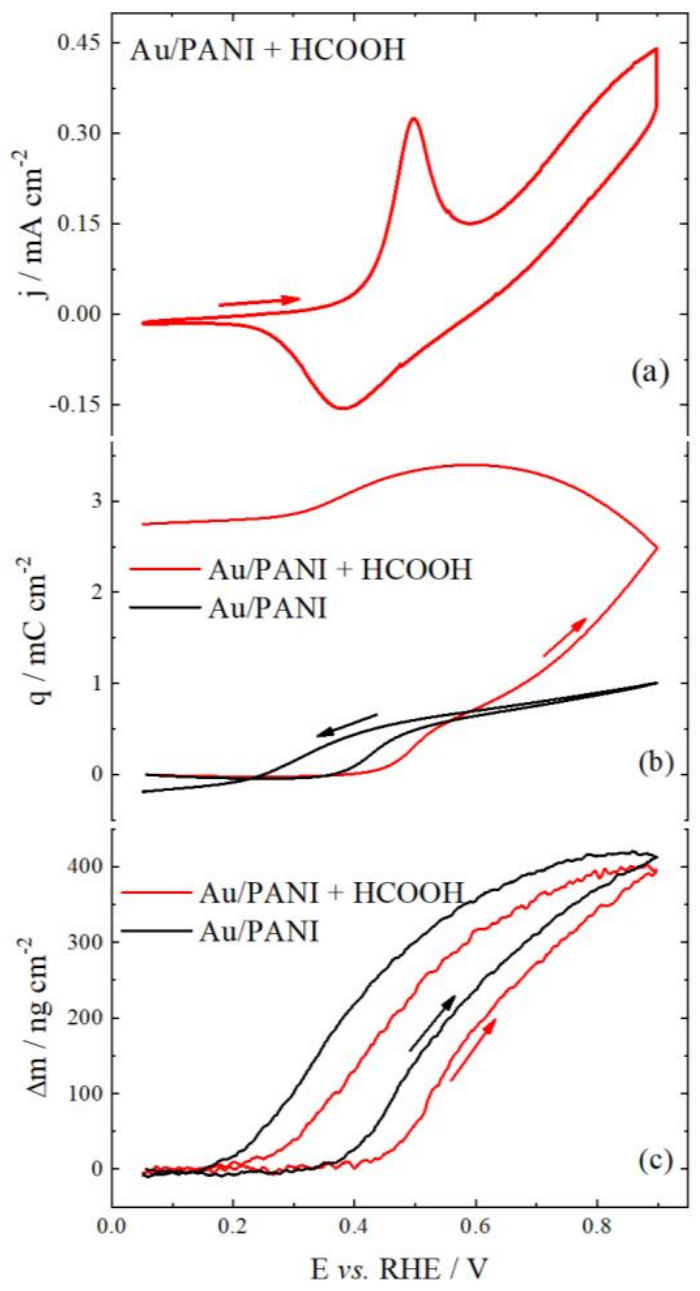

Figure 6: Voltammetric (a) $j / E$, (b) $q / E$, and (c) $\Delta m / E$ profiles (recorded at $50 \mathrm{mV}$ $\mathrm{s}^{-1}$ ) for the Au/PANI modified electrode in the presence of $1 \mathrm{~mol} \mathrm{~L}^{-1} \mathrm{HCOOH} . q / E$ and $\triangle m / E$ in the absence of $\mathrm{HCOOH}$ is also given for reference, see also Figure 1(a). Electrolyte: aqueous solution containing $0.5 \mathrm{~mol} \mathrm{~L}^{-1} \mathrm{H}_{2} \mathrm{SO}_{4}$. Current and mass were normalized by the geometric area of the electrode.

The first aspect to be stressed in this figure is the excess of anodic charge evidenced by the reaction currents above $0.60 \mathrm{~V}$, due to the electro-oxidation of formic acid on the Au surface underneath the PANI film. This further illustrates the porous nature (or nonuniform deposition of PANI) of the PANI, through which $\mathrm{HCOOH}$ molecules can diffuse and reach the gold surface. The electric charges depicted in Figure 6(b) clearly show the excess of charge due to the oxidation of $\mathrm{HCOOH}$. Despite this considerable difference, the contribution of the $\mathrm{HCOOH}$ oxidation barely affects the mass variations, which confirms that the charge compensation within the PANI, i.e., a volumetric process, is the main responsible for the $\Delta m / E$ response. In other words, in this experimental arrangement, $q / E$ results reflect the surface electrocatalytic 
processes, and the $\Delta m / E$ profile informs the volumetric ones with the PANI film. This result can be compared with that for the Au/PANI and Au/PANI/Pt electrodes, as presented above but in terms of the $q / E$ and $\Delta m / E$ profiles, c.f. Figure S5 in the Supporting Information file. Differently from the situation just discussed, those experiments were performed in base electrolyte, and results in $q / E$ and $\Delta m / E$ remain nearly unaffected by the presence of Pt and the response is dominated by the volumetric processes.

Following this reasoning, we now discuss the electro-oxidation of $\mathrm{HCOOH}$ on PANIcovered platinum electrode. Figure 7 shows the time-invariant voltammetric and nanogravimetric responses for Pt/PANI electrodes before and after addition of $\mathrm{HCOOH}$, results on bare Pt is also given for comparison. Data for the platinum electrode were already presented in Figure 3, and the results presented here are for a restricted potential window. The narrower potential region is necessary to allow the comparison with the Pt/PANI electrode, whose structure can be damaged at high potentials, as already discussed. Results in base electrolyte, Figure 7(a) and (b), show the hydrogen region on Pt electrode with the characteristic peaks of adsorption/desorption of $\mathrm{H}_{\text {upd, }}$, while on Pt/PANI the characteristic peaks of oxidation/reduction of PANI prevails. The $\Delta m / E$ responses in Figure $7(\mathrm{~b})$ are completely different and, as in the case of the cyclic voltammograms, they reflect volumetric and surface signatures on Pt/PANI and Pt electrodes, respectively. 

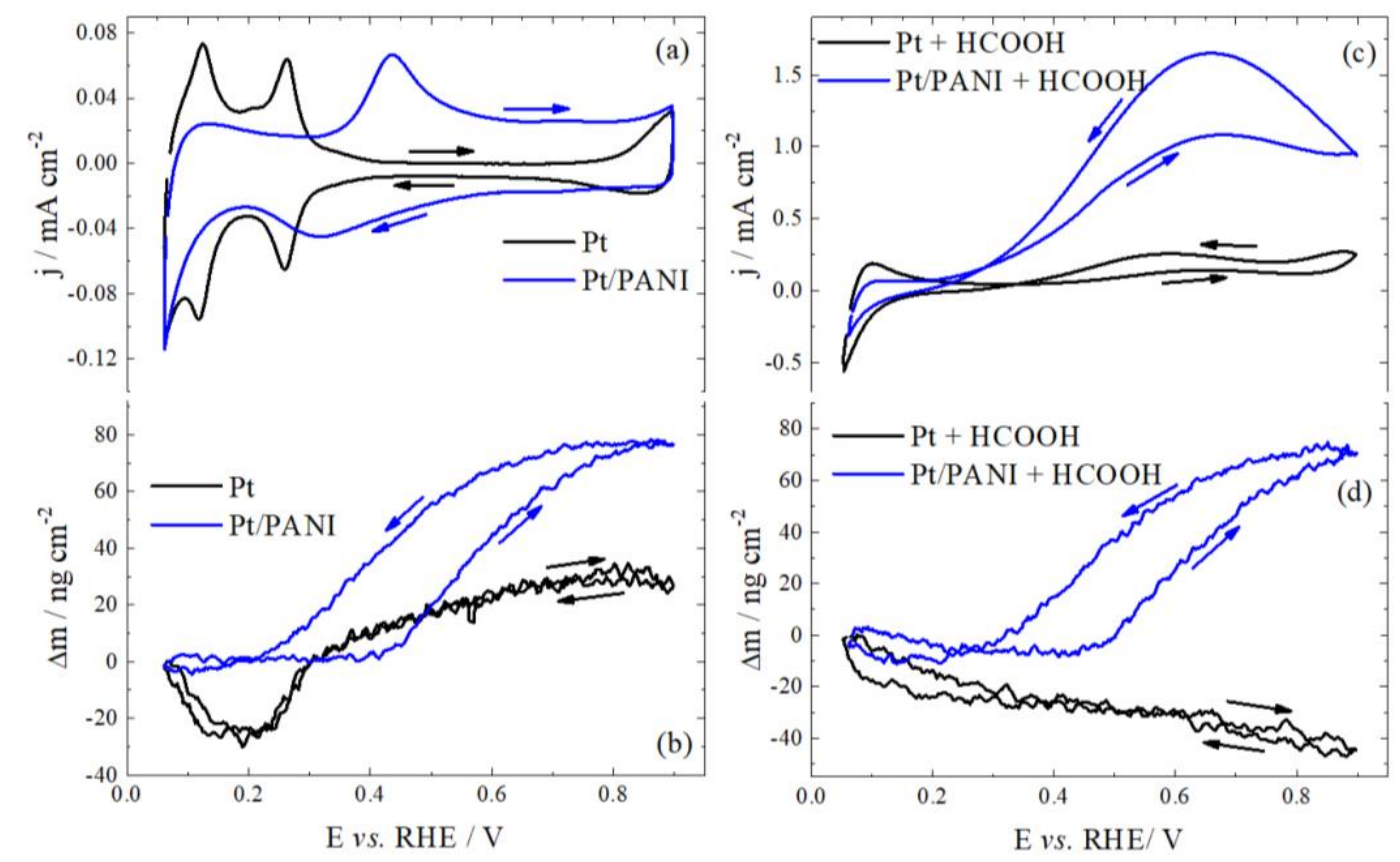

Figure 7: Voltammetric $j / E$ and $\Delta m / E$ profiles (recorded at $50 \mathrm{mV} \mathrm{s}^{-1}$ ) in (a) and (b) aqueous solution containing $0.5 \mathrm{~mol} \mathrm{~L}^{-1} \mathrm{H}_{2} \mathrm{SO}_{4}$, and (c) and (d) after addition of $\mathrm{HCOOH}\left(1 \mathrm{~mol} \mathrm{~L}^{-1}\right)$, for Pt (black) and Pt/PANI (blue) electrodes. Current and mass were normalized by the real area, as determined by the hydrogen region for the bare platinum electrode.

Figure 7(c) shows the voltammetric results of the electro-oxidation of formic acid on Pt/PANI and on Pt electrodes. As in the case of Au/PANI/Pt electrodes (Figure 3 (b)), the higher activity towards the electro-oxidation of formic acid is also observed on Pt/PANI. The high currents, the lower onset potential and, importantly, the negligible hysteresis between positiveand negative-going sweeps clearly attests the higher activity of the Pt/PANI electrode. The high activity of the Pt/PANI electrode towards the electro-oxidation of formic acid, a surface process, evidenced in Figure 7(c), does not result in detectable difference in the $\Delta m / E$ profile in Figure 7(d). Indeed, $\Delta m / E$ responses for the Pt/PANI electrode is dominated by the, volumetric, charge compensation processes irrespective to the presence of $\mathrm{HCOOH}$. The $\Delta m / E$ response for the Pt electrode in the presence of $\mathrm{HCOOH}$, Figure $7(\mathrm{~d})$, is completely different and reflects mainly the adsorption and adsorbate oxidation, i.e., surface.

Oscillatory electro-oxidation of $\mathrm{HCOOH}$ on Pt/PANI electrodes. Planes et al., ${ }^{18}$ studied the electro-oxidation of methanol Pt/PANI catalyst, using in situ FTIR spectroscopy coupled with electrochemical experiments. The authors observed that the presence of PANI considerably changes the reaction mechanism by suppressing the formation of $\mathrm{CO}_{\mathrm{ad}}$, the main poisoning species that inhibits the overall reaction. Based on this finding we decided to investigate the 
existence of oscillations in the electro-oxidation of formic acid on Pt/PANI. Results of a slow galvanodynamic sweep are given in Figure 8, in terms of the electrode potential and mass variations. As in the case of the $\mathrm{Au} / \mathrm{PANI} / \mathrm{Pt}+\mathrm{HCOOH}$ system, Table 1 , oscillations $E / t$ and $\Delta m / t$ are in-phase, evidencing that the charge compensation within the polymer matrix governs the mass variation.

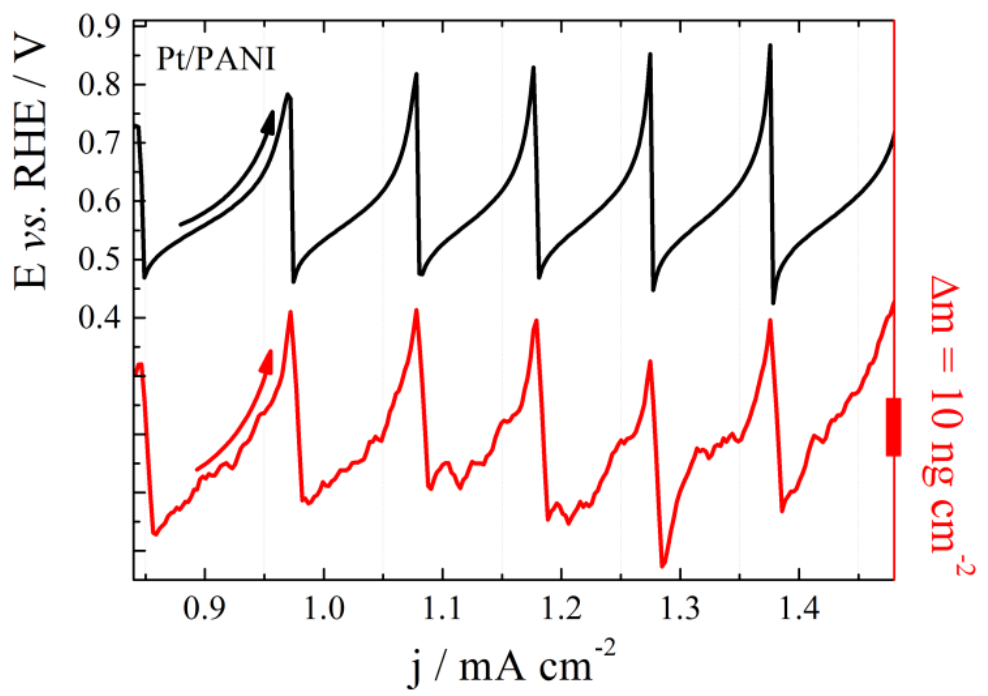

Figure 8: Galvanodynamic sweep $\left(1.5 \mu \mathrm{A} \mathrm{s}^{-1}\right)$ for the electro-oxidation of $\mathrm{HCOOH}$ on Pt/PANI electrode. Electrolyte: aqueous solution containing $0.5 \mathrm{~mol} \mathrm{~L}^{-1} \mathrm{H}_{2} \mathrm{SO}_{4}$ and $1 \mathrm{~mol} \mathrm{~L}{ }^{-1} \mathrm{HCOOH}$.

There is apparently no spectroscopic data for the oxidation of formic acid on Pt/PANI, to confirm that the formation of $\mathrm{CO}_{\mathrm{ad}}$ is suppressed as the case of methanol, ${ }^{18}$ but the unambiguous increase in the activity is a hint that this process could be inhibited, if not suppressed. Indeed, the already mentioned decrease in the onset potential for the oxidation of $\mathrm{HCOOH}$ and the high ratio between the oxidation peaks in backward and forward scans suggest the tolerance of PANI-modified catalysts for the formation of $\mathrm{CO}$. The, previously unreported, occurrence of potential oscillations in the electro-oxidation of formic acid on Pt/PANI modified arises an interesting question. In fact, there are spectroscopic evidences that adsorbed $\mathrm{CO}$ plays a central role during the oscillatory electro-oxidation of formic acid on platinum, ${ }^{54}$ and in all models and kinetics analysis, see ${ }^{55}$ and references therein, the coverage of $\mathrm{CO}$ is considered an essential variable. The possibility of the emergence of oscillations in the electro-oxidation of formic acid on platinum without the participation of $\mathrm{CO}_{\mathrm{ad}}$ can reveal important mechanistic details of this system and must be further investigated. 


\section{Conclusions ANd Perspectives}

Conducting polymers such as polyaniline and polypyrrole have been used as support for catalysts towards different electrochemical reactions. The overall activity of the modified interfaces depends on both the processes on the catalyst surface and of the charge compensation within the polymer matrix. Therefore, understand the coupling between surface and volumetric processes in such systems is of utmost importance. Herein we report on the experimental investigation of the interplay between surface and volumetric processes during the electrooxidation of formic acid (and also formaldehyde) on platinum modified polyaniline electrodes. The study was carried out by means of in situ nanogravimetry, with the Electrochemical Quartz Crystal Nanobalance (EQCN). We have explored the dynamics of charge and mass changes along several experimental conditions, including the self-organized potential oscillations. The systematic study included the analysis of several configurations: gold electrodes covered with a PANI film and dispersed platinum (Au/PANI/Pt); platinum electrodes covered with PANI (Pt/PANI); and bare platinum electrodes.

The current and mass changes profiles for the redox processes in Au/PANI and $\mathrm{Au} / \mathrm{PANI} / \mathrm{Pt}$ modified electrodes in aqueous sulfuric acid solutions are dominated by the charge compensation processes within the film. Both the voltammetric profiles and the dynamics of charge compensation is only slightly affected by the presence of the platinum nanoparticles within the PANI film.

The Au/PANI/Pt modified electrode was found to be more active than conventional platinum electrode towards the electro-oxidation of formic acid. In particular, the high reversibility in the cyclic voltammogram on the $\mathrm{Au} / \mathrm{PANI} / \mathrm{Pt}$ electrode suggests that the reaction proceeds without the formation of adsorbed carbon monoxide, $\mathrm{CO}_{\mathrm{ad}}$, in agreement with previously published data with methanol. ${ }^{18}$ The $\Delta m / E$ profile for the Au/PANI/Pt electrode remains unaffected by the presence of formic acid, indicating the prevalence of the volumetric effects due to the charge compensation processes within the film. This observation was further confirmed by the introduced $d(\Delta m) / d t v s$. E plots, which nicely emulated the voltammetric response of the volumetric processes within the film, recorded simultaneously to the conventional voltammetric response ruled by the surface electro-oxidation of formic acid on platinum dispersed in the polymeric matrix. The procedure to decouple both processes can be employed to the study of several systems, including applications such as supported catalysts for 
energy conversion systems and actuators. Studies in this direction are currently in progress in our Group.

The electro-oxidation of formic acid was also studied on Pt/PANI and on Pt electrodes. As in the case of Au/PANI/Pt electrodes, the high currents, the lower onset potential and, importantly, the negligible hysteresis between positive- and negative-going sweeps clearly attests the higher activity of the Pt/PANI electrode. Furthermore, the $\Delta m / E$ response for the $\mathrm{Pt} / \mathrm{PANI}$ electrode is also dominated by the, volumetric, charge compensation processes irrespective to the presence of $\mathrm{HCOOH}$; whereas the $j / E$ response reflects the conventional surface electro-oxidation on platinum.

The use of oscillatory electrochemical reactions is an emergent possibility to control films and gels by electrical stimuli in order to generate self-oscillating autonomous mechanical response in such systems. ${ }^{28}$ Furthermore, we have explored the emergence and evolution of self-organized oscillations in electrocatalytic systems as a mean to investigate mechanistic aspects. ${ }^{55}$ In the case of PANI modified electrodes, we found that potential oscillations are strongly influenced by the charge compensation processes within the electroactive film and we were able to decouple the surface and volumetric processes. An intriguing and previously unreported result found was the occurrence of potential oscillations during the electro-oxidation of formic acid on Pt/PANI, where, in principle, the formation of that adsorbed $\mathrm{CO}$ is suppressed. There are abundant evidences that $\mathrm{CO}_{\mathrm{ad}}$ plays a central role during the oscillatory electro-oxidation of formic acid on platinum. ${ }^{54,55}$ This, rather surprising, finding certainly deserve further investigation.

\section{ACKNOWLEDGMENTS}

GCAF acknowledges Coordenação de Aperfeiçoamento de Pessoal de Nível Superior - Brasil (CAPES)/PROEX for financial support. HV (grant \#306060/2017-5) acknowledges Conselho Nacional de Desenvolvimento Científico e Tecnológico (CNPq) for financial support. HV (grants \#2013/16930-7 and \#2019/22183-6) and RMT (grant \#2015/26308-7) acknowledge São Paulo Research Foundation (FAPESP) for financial support. The authors acknowledge Dr. Murilo F. Cabral for helping with the EQCN setup. This study was partially financed by the CAPES - Finance Code 001. The authors acknowledge CAPES/COFECUB project Ch. 74712 and Ch. 914-18. TWN acknowledge financial support from the European Union (ERDF) and Région Nouvelle Aquitaine. 


\section{REFERENCES}

(1) MacDiarmid, A. G. "Synthetic Metals": A Novel Role for Organic Polymers (Nobel Lecture). Angew. Chemie Int. Ed. 2001, 40 (14), 2581-2590. https://doi.org/10.1002/15213773(20010716)40:14<2581::AID-ANIE2581>3.0.CO;2-2.

(2) Heeger, A. J. Semiconducting and Metallic Polymers: The Fourth Generation of Polymeric Materials. Curr. Appl. Phys. 2001, 1 (14), 2591-2611. https://doi.org/10.1016/S15671739(01)00053-0.

(3) Geniès, E. M.; Boyle, A.; Lapkowski, M.; Tsintavis, C. Polyaniline: A Historical Survey. Synthetic Metals. Elsevier June 1, 1990, pp 139-182. https://doi.org/10.1016/03796779(90)90050-U.

(4) Malinauskas, A. Chemical Deposition of Conducting Polymers. Polymer (Guildf). 2001, 42 (9), 3957-3972. https://doi.org/10.1016/S0032-3861(00)00800-4.

(5) Gholamian, M.; Sundaram, J.; Contractor, A. Q. Oxidation of Formic Acid at PolyanilineCoated and Modified-Polyaniline-Coated Electrodes. Langmuir 1987, 3 (5), 741-744. https://doi.org/10.1021/la00077a030.

(6) Lamy, C.; Leger, J.-M.; Garnier, F. Electrocatalytic Properties of Conductive Polymers. In Organic Conductive Molecules and Polymers: Vol. 3. Conductive Polymers: Spectroscopy and Physical Properties; H. S. Nalwa, Ed.; John Wiley and Sons, 1997; pp 471-493.

(7) Podlovchenko, B. I.; Andreev, V. N. Electrocatalysis on Polymer-Modified Electrodes. Russ. Chem. Rev. 2002, 71 (10), 837-851. https://doi.org/10.1070/RC2002v071n10ABEH000672.

(8) Laborde, H.; Léger, J.-M.; Lamy, C. Electrocatalytic Oxidation of Methanol and C1 Molecules on Highly Dispersed Electrodes Part II: Platinum-Ruthenium in Polyaniline. J. Appl. Electrochem. 1994, 24 (10), 1019-1027. https://doi.org/10.1007/bf00241194.

(9) Napporn, W. T.; Laborde, H.; Léger, J.-M.; Lamy, C. Electro-Oxidation of C1 Molecules at PtBased Catalysts Highly Dispersed into a Polymer Matrix: Effect of the Method of Preparation. J. Electroanal. Chem. 1996, 404 (1), 153-159. https://doi.org/10.1016/0022-0728(95)04333-0.

(10) Olivi, P.; Bulhões, L. O. S.; Léger, J. M.; Hahn, F.; Beden, B.; Lamy, C. The Electrooxidation of Formaldehyde on $\mathrm{Pt}(100)$ and $\mathrm{Pt}(110)$ Electrodes in Perchloric Acid Solutions. Electrochim. Acta 1996, 41 (6), 927-932. https://doi.org/10.1016/0013-4686(95)00387-8.

(11) Fiçıcıoğlu, F.; Kadırgan, F. Electrooxidation of Methanol on Platinum Doped Polyaniline Electrodes: Deposition Potential and Temperature Effect. J. Electroanal. Chem. 1997, 430 (12), 179-182. https://doi.org/10.1016/S0022-0728(97)00165-4.

(12) Inzelt, G.; Kertész, V. Effect of Poly(Aniline) Pseudocapacitance on Potential and EQCM Frequency Oscillations Arising in the Course of Galvanostatic Oxidation of Formic Acid on Platinum. Electrochim. Acta 1997, 42 (2), 229-235. https://doi.org/10.1016/00134686(96)00148-X.

(13) Kelaidopoulou, A.; Papoutsis, A.; Kokkinidis, G.; Napporn, W. T.; Leger, J. M.; Lamy, C. Electrooxidation of $\beta-\mathrm{D}(+)$ Glucose on Bare and u.p.d. Modified Platinum Particles Dispersed in Polyaniline. J. Appl. Electrochem. 1999, 29 (1), 101-107. https://doi.org/10.1023/A:1003433206439.

(14) Fungaro, D. A.; Oliveira-Neto, A.; Linardi, M. Electrocatalytic Oxidation of Ethanol on 
Platinum Nanoparticles Modified Polyaniline Electrode. Lat. Am. Appl. Res. 2007, 37 (3), $223-$ 226.

(15) Moghaddam, R. B.; Ali, O. Y.; Javashi, M.; Warburton, P. L.; Pickup, P. G. The Effects of Conducting Polymers on Formic Acid Oxidation at Pt Nanoparticles. Electrochim. Acta 2015, 162, 230-236. https://doi.org/10.1016/j.electacta.2014.08.029.

(16) Sun, X.; Zhang, N.; Huang, X. Polyaniline-Coated Platinum Nanocube Assemblies as Enhanced Methanol Oxidation Electrocatalysts. ChemCatChem 2016, 8 (22), 3436-3440. https://doi.org/10.1002/cctc.201600923.

(17) Kessler, T.; Castro Luna, A. M. Catalytic Polyaniline-Supported Electrodes for Application in Electrocatalysis. J. Solid State Electrochem. 2003, 7 (9), 593-598.

https://doi.org/10.1007/s10008-003-0360-5.

(18) Planes, G. A.; Rodríguez, J. L.; Pastor, E.; Barbero, C. Evidence of a Free Pt Surface under Electrodeposited Polyaniline (PANI) Films: CO Adsorption and Methanol Oxidation at PANI/Pt without Metal Particles. Langmuir 2003, 19 (20), 8137-8140. https://doi.org/10.1021/la0346043.

(19) Buttry, D. A.; Ward, M. D. Measurement of Interfacial Processes at Electrode Surfaces with the Electrochemical Quartz Crystal Microbalance. Chem. Rev. 1992, 92 (6), 1355-1379. https://doi.org/10.1021/cr00014a006.

(20) Deakin, M. R.; Buttry, D. A. Electrochemical Applications of the Quartz Crystal Microbalance; American Chemical Society, 1989; Vol. 61, pp 1147 A-1154 A. https://doi.org/10.1021/ac00195a001.

(21) Maia, G.; Torresi, R. M.; Ticianelli, E. A.; Nart, F. C. Charge Compensation Dynamics in the Redox Processes of Polypyrrole-Modified Electrodes. J. Phys. Chem. 1996, 100 (39), 1591015916. https://doi.org/10.1021/jp9607780.

(22) Hillman, A. R. The Electrochemical Quartz Crystal Microbalance. In Encyclopedia of Electrochemistry; Bard, A. J., Stratmann, M., Eds.; Wiley-VCH Verlag GmbH \& Co.: Weinheim, 2003. https://doi.org/10.1002/9783527610426.bard030207.

(23) Inzelt, G. Electrochemical Quartz Crystal Nanobalance. In Electroanalytical Methods; Springer Berlin Heidelberg: Berlin, Heidelberg, 2010; pp 257-270. https://doi.org/10.1007/978-3-64202915-8_13.

(24) Yang, Y.; Xiong, Y.; Zeng, R.; Lu, X.; Krumov, M.; Huang, X.; Xu, W.; Wang, H.; DiSalvo, F. J.; Brock, J. D.; et al. Operando Methods in Electrocatalysis. ACS Catal. 2021, 1136-1178. https://doi.org/10.1021/acscatal.0c04789.

(25) Varela, H.; Malta, M.; Torresi, R. M. Low Cost in Situ Techniques in Electrochemistry: The Quartz Crystal Microbalance. Quim. Nova 2000, 23 (5), 664-679.

https://doi.org/10.1590/S0100-40422000000500016.

(26) Sauerbrey, G. Verwendung von Schwingquarzen Zur Wägung Dönner Schichten Und Zur Mikrowägung. Zeitschrift für Phys. 1959, 155 (2), 206-222. https://doi.org/10.1007/BF01337937.

(27) Varela, H.; Torresi, R. M. Ionic Exchange Phenomena Related to the Redox Processes of Polyaniline in Nonaqueous Media. J. Electrochem. Soc. 2000, 147 (2), 665. https://doi.org/10.1149/1.1393250.

(28) Shahinpoor, M.; Kim, K. J. Ionic Polymer-Metal Composites: III. Modeling and Simulation as Biomimetic Sensors, Actuators, Transducers, and Artificial Muscles. Smart Mater. Struct. 
2004, 13 (6), 1362-1388. https://doi.org/10.1088/0964-1726/13/6/009.

(29) Kim, D.; Kim, K. J. Ionic Polymer-Metal Composite Actuators Exhibiting Self-Oscillation. Sensors Actuators A Phys. 2007, 137 (1), 5. https://doi.org/10.1016/j.sna.2007.02.010.

(30) Kim, K. J.; Tadokoro, S. Electroactive Polymers for Robotic Applications - Artificial Muscles and Sensors; Springer: London, 2007.

(31) Hachkar, M.; Beden, B.; Lamy, C. Oscillating Electrocatalytic Systems. Part I. Survey of Systems Involving the Oxidation of Organics and Detailed Electrochemical Investigation of Formaldehyde Oxidation on Rhodium Electrodes. J. Electroanal. Chem. 1990, 287 (1), 81-98. https://doi.org/10.1016/0022-0728(90)87161-C.

(32) Krischer, K.; Varela, H. Oscillations and Other Dynamic Instabilities. In Handbook of Fuel Cells; Vielstich, W., Lamm, A., Gasteiger, H. A., Eds.; John Wiley \& Sons, Ltd: Chichester, UK, 2010; Vol. 2, pp 679-701. https://doi.org/10.1002/9780470974001.f206052.

(33) Varela, H.; Delmonde, M. V. F.; Zülke, A. A. The Oscillatory Electrooxidation of Small Organic Molecules. In Electrocatalysts for Low Temperature Fuel Cells; Maiyalagan, T., Saji, V. S., Eds.; Wiley-VCH Verlag GmbH \& Co. KGaA: Weinheim, Germany, 2017; pp 145-163. https://doi.org/10.1002/9783527803873.ch5.

(34) Machado, E. G.; Varela, H. Kinetic Instabilities in Electrocatalysis. In Encyclopedia of Interfacial Chemistry; Elsevier, 2018; pp 701-718. https://doi.org/10.1016/b978-0-12-4095472.13369-4.

(35) Venancio, E. C.; Napporn, T. W. W.; Motheo, A. J. Electro-Oxidation of Glycerol on Platinum Dispersed in Polyaniline Matrices. Electrochim. Acta 2002, 47 (9), 7.

https://doi.org/10.1016/S0013-4686(01)00877-5.

(36) Stilwell, D. E.; Park, S.-M. S. Electrochemistry of Conductive Polymers: III . Some Physical and Electrochemical Properties Observed from Electrochemically Grown Polyaniline. $J$. Electrochem. Soc. 1988, 135 (10), 2491-2496. https://doi.org/10.1149/1.2095364.

(37) Gospodinova, N.; Terlemezyan, L. Conducting Polymers Prepared by Oxidative Polymerization: Polyaniline. Progress in Polymer Science (Oxford). Elsevier Ltd December 1, 1998, pp 1443-1484. https://doi.org/10.1016/S0079-6700(98)00008-2.

(38) Pournaghi-Azar, M. H.; Habibi, B. Electropolymerization of Aniline in Acid Media on the Bare and Chemically Pre-Treated Aluminum Electrodes. A Comparative Characterization of the Polyaniline Deposited Electrodes. Electrochim. Acta 2007, 52 (12), 4222-4230. https://doi.org/10.1016/j.electacta.2006.11.050.

(39) Elkais, A. R.; Gvozdenović, M. M.; Jugović, B. Z.; Stevanović, J. S.; Nikolić, N. D.; Grgur, B. N. Electrochemical Synthesis and Characterization of Polyaniline Thin Film and Polyaniline Powder. Prog. Org. Coatings 2011, 71 (1), 32-35. https://doi.org/10.1016/j.porgcoat.2010.12.004.

(40) Abd El-Moghny, M. G.; Alalawy, H. H.; Mohammad, A. M.; Mazhar, A. A.; El-Deab, M. S.; El-Anadouli, B. E. Conducting Polymers Inducing Catalysis: Enhanced Formic Acid ElectroOxidation at a Pt/Polyaniline Nanocatalyst. Int. J. Hydrogen Energy 2017, 42 (16), 1116611176. https://doi.org/10.1016/j.ijhydene.2017.01.157.

(41) Cordoba-Torresi, S.; Gabrielli, C.; Keddam, M.; Takenouti, H.; Torresi, R. Role of Ion Exchange in the Redox Processes of a Polyaniline Film Studied by an Ac Quartz Crystal Microbalance. J. Electroanal. Chem. 1990, 290 (1-2), 269-274. https://doi.org/10.1016/00220728(90)87437-O. 
(42) Torresi, R. M.; de Torresi, S. I. C.; Gabrielli, C.; Keddam, M.; Takenouti, H. Quartz Crystal Microbalance Characterization of Electrochemical Doping of Polyaniline Films. Synth. Met. 1993, 61 (3), 291-296. https://doi.org/10.1016/0379-6779(93)91275-7.

(43) Varela, H.; Maranhão, S. L. A.; Mello, R. M. Q.; Ticianelli, E. A.; Torresi, R. M. Comparisons of Charge Compensation Process in Aqueous Media of Polyaniline and Self-Doped Polyanilines. Synth. Met. 2001, 122 (2), 321-327. https://doi.org/10.1016/S03796779(00)00359-3.

(44) Herrero, E.; Feliu, J. M. Understanding Formic Acid Oxidation Mechanism on Platinum Single Crystal Electrodes. Curr. Opin. Electrochem. 2018, 9, 145-150. https://doi.org/10.1016/j.coelec.2018.03.010.

(45) Hachkar, M.; Napporn, T.; Léger, J. M.; Beden, B.; Lamy, C. An Electrochemical Quartz Crystal Microbalance Investigation of the Adsorption and Oxidation of $\mathrm{CO}$ on a Platinum Electrode. Electrochim. Acta 1996, 41 (17), 2721-2730. https://doi.org/10.1016/00134686(96)00127-2.

(46) Zhang, J.; Datta, R. Higher Power Output in a PEMFC Operating under Autonomous Oscillatory Conditions in the Presence of CO. Electrochem. Solid-State Lett. 2004, 7 (3), A37. https://doi.org/10.1149/1.1643593.

(47) Delmonde, M. V. F.; Sallum, L. F.; Perini, N.; Gonzalez, E. R.; Schlögl, R.; Varela, H. Electrocatalytic Efficiency of the Oxidation of Small Organic Molecules under Oscillatory Regime. J. Phys. Chem. C 2016, 120 (39), 22365-22374.

https://doi.org/10.1021/acs.jpcc.6b06692.

(48) Nogueira, J. A.; Varela, H. Direct Liquid Fuel Cells-The Influence of Temperature and Dynamic Instabilities. Energy \& Fuels 2020, 34 (10), 12995-13009. https://doi.org/10.1021/acs.energyfuels.0c02491.

(49) Melle, G. B.; Altair, T.; Romano, R. L.; Varela, H. Electrocatalytic Efficiency of the Oxidation of Ethylene Glycol, Glycerol, and Glucose under Oscillatory Regime. Energy \& Fuels 2021, 35 (7), 6202-6209. https://doi.org/10.1021/acs.energyfuels.1c00203.

(50) Inzelt, G.; Kertész, V. Experimental Evidence for the Periodical Changes of the Amount of Chemisorbed Species Accompanying the Potential Oscillations Produced in the Course of Galvanostatic Oxidation of Formic Acid on Platinum. Electrochim. Acta 1993, 38 (16), 23852386. https://doi.org/10.1016/0013-4686(93)85106-9.

(51) Inzelt, G.; Kertész, V.; Láng, G. Simultaneous Oscillations of the Surface Mass and Potential in the Course of the Galvanostatic Oxidation of 2-Propanol. J. Phys. Chem. 1993, 97 (23), 61046106. https://doi.org/10.1021/j100125a002.

(52) Inzelt, G.; Kertész, V. Enhanced Frequency Oscillations Accompanying Galvanostatic Potential Oscillations at Pt Electrode in Cu2+ Formic Acid Systems. Electrochim. Acta 1995, 40 (2), 221-225. https://doi.org/10.1016/0013-4686(94)00297-E.

(53) Tian, M.; Conway, B. E. Electrocatalysis in Oscillatory Kinetics of Anodic Oxidation of Formic Acid: At Pt; Nanogravimetry and Voltammetry Studies on the Role of Reactive Surface Oxide. J. Electroanal. Chem. 2008, 616 (1-2), 45-56. https://doi.org/10.1016/j.jelechem.2007.12.016.

(54) Samjeské, G.; Miki, A.; Ye, S.; Yamakata, A.; Mukouyama, Y.; Okamoto, H.; Osawa, M. Potential Oscillations in Galvanostatic Electrooxidation of Formic Acid on Platinum: A TimeResolved Surface-Enhanced Infrared Study. J. Phys. Chem. B 2005, 109 (49), 23509-23516. https://doi.org/10.1021/jp055220j. 
(55) Calderón-Cárdenas, A.; Hartl, F. W.; Gallas, J. A. C.; Varela, H. Modeling the Triple-Path Electro-Oxidation of Formic Acid on Platinum: Cyclic Voltammetry and Oscillations. Catal. Today 2021, 359, 90-98. https://doi.org/10.1016/j.cattod.2019.04.054. 